\title{
A method of monitoring function in corticospinal pathways during scoliosis surgery with a note on motor conduction velocities
}

\author{
SG BOYD, ${ }^{*}$ JC ROTHWELL, $\dagger$ JMA COWAN, $\dagger$ PJ WEBB, ${ }^{*}$ T MORLEY, $\dagger$ \\ P ASSELMAN, $\dagger$ CD MARSDEN†
}

From the Departments of Clinical Neurophysiology and Orthopaedics, The Hospital for Sick Children, Great Ormond Street, ${ }^{*}$ and Departments of Neurology and Orthopaedics, King's College Hospital School of Medicine and Dentistry, $\dagger$ London, $U K$

SUMMARY Spinal cord potentials produced by high voltage electrical stimulation of the scalp over the motor cortex were recorded intraoperatively from bipolar electrodes inserted into the epidural space of eleven patients undergoing corrective surgery for scoliosis. Responses to single stimuli could be recorded from the cord at all levels from cervical to low thoracic regions. The potentials were larger in the cervical than in the thoracic region and sometimes were followed by later waves at high stimulation intensities. Conduction velocity in large corticomotoneuron fibres was estimated to be between $50-74 \mathrm{~ms}^{-1}$ in different patients. This technique for monitoring motor tract function may be a useful adjunct to conventional monitoring of the sensory pathways during surgery.

Corrective operations on the spinal column for scoliosis carry a risk of serious neurological damage. This is quite small during Harrington rod instrumentation $(0.4 \%)$, but is substantially higher during anterior approaches to the column such as the Zielke operation. ${ }^{1}$ Apart from the "wake-up" test, ${ }^{2}$ all current techniques of monitoring spinal cord function rely upon recording activity in sensory pathways. Many involve stimulation of peripheral nerves and recording of averaged somatosensory evoked responses (SEPs) at one of several sites, which may include the scalp, the exposed spinous processes, intervertebral ligaments, or from fine electrodes inserted into the epidural space (see ref $^{3}$ for a compilation of papers). Japanese workers have devised a technique in which the spinal cord is stimulated directly at a high level through epidural electrodes, and recordings made from lower levels. ${ }^{4-6}$ However, even this method preferentially stimulates sensory tracts, and it is now believed that descending motor pathways contribute little to these evoked responses. ${ }^{\text {p }}$

Several lines of evidence suggest that it may be

Address for reprint requests: Dr SG Boyd, Hospital for Sick Children, Great Ormond Street, London WC1N 3JH, UK.

Received 2 April 1985. Accepted 25 May 1985 important to monitor motor as well as sensory tracts in the spinal cord. There are a number of clinical reports showing the failure of sensory monitoring to reveal motor deficits produced during operations. ${ }^{8}$ It has also been found in cats that experimentally induced cord ischaemia can result in damage to descending systems which may not be detected by monitoring SEPs. ${ }^{9}$ Despite these findings, only Levy and York and their colleagues have attempted techniques which allow assessment of motor pathways. ${ }^{10-13}$ They used two methods to activate motor tracts: direct stimulation of the dorsolateral part of the spinal cord exposed during surgery, ${ }^{11}$ and transcranial (palate to scalp) stimulation of brainstem pathways. ${ }^{13}$ Both these techniques produced descending volleys in the cord and, in some cases, visible muscle contraction in the hands and feet. However, there was no guarantee that the signals recorded from the spinal cord were not contaminated by activity in sensory fibres.

We have devised a different method for monitoring function in corticospinal pathways during surgery. Descending motor pathways are stimulated through the intact scalp, using the technique of Merton and Morton. $^{14}$ The descending motor volley is then recorded from the spinal cord with bipolar epidural electrodes. This has advantages over other methods in that only single scalp stimuli are needed to produce 
Table 1 Summary of patients studied and recording sites used in each patient

\begin{tabular}{|c|c|c|c|c|c|c|c|}
\hline Patient & Sex & $\begin{array}{l}\text { Age } \\
\text { (years) }\end{array}$ & Diagnosis & Operation & Cervical & $\begin{array}{l}\text { Electrodes } \\
\text { thoracic }\end{array}$ & Oesophageal \\
\hline LH & $\mathbf{F}$ & $13 \cdot 10$ & Marfan's disease & Harrington Rod & + & & \\
\hline EL & $\mathbf{M}$ & $14 \cdot 5$ & Hemivertebra & $\begin{array}{l}\text { Harrington Rod } \\
\text { Posterior fusion }\end{array}$ & + & + & \\
\hline SB & $\mathbf{F}$ & & Idiopathic scoliosis & Posterior fusion & + & & + \\
\hline PH & $\mathbf{M}$ & $16 \cdot 3$ & Myotonic Dystrophy & Luque & + & & \\
\hline KA & $\mathbf{F}$ & $9 \cdot 10$ & $\begin{array}{l}\text { Congenital hemivertebra } \\
\text { Spinal dysraphism }\end{array}$ & $\begin{array}{l}\text { Harrington Rod } \\
\text { Posterior fusion }\end{array}$ & + & & \\
\hline DK & $\mathbf{F}$ & $12 \cdot 10$ & Spinal Muscular Atrophy & Luque & + & & \\
\hline WJ & $\mathbf{M}$ & & $\begin{array}{l}\text { Adolescent idiopathic } \\
\text { Scoliosis }\end{array}$ & $\begin{array}{l}\text { Harrington Rod } \\
\text { Posterior fusion }\end{array}$ & & + & + \\
\hline AR & $\mathbf{F}$ & 17 & Adolescent idiopathic & Harrington Rod & & + & + \\
\hline & & & Scoliosis & Posterior fusion & & & \\
\hline SC & $\mathbf{F}$ & $15 \cdot 7$ & Congenital heart disease & $\begin{array}{l}\text { Harrington Rod } \\
\text { Posterior fusion }\end{array}$ & + & & \\
\hline SS & $\mathbf{F}$ & $13 \cdot 10$ & Leber's Amaurosis & $\begin{array}{l}\text { Harrington Rod } \\
\text { Posterior fusion }\end{array}$ & + & & + \\
\hline $\mathrm{CA}$ & $\mathbf{M}$ & $7 \cdot 1$ & Congenital scoliosis & Posterior fusion & + & + & + \\
\hline
\end{tabular}

clear motor volleys rather than averaging many separate responses. Also, it is highly unlikely that this method of stimulation activates sensory pathways (see discussion). In addition, we have been able to acquire data on conduction velocities of these signals in the human corticospinal tracts. A preliminary communication of some of these experiments has already been published. ${ }^{15}$

\section{Methods}

Details of the patients' ages, diagnoses and surgical procedures are given in table 1 . Patients with epilepsy were excluded. None of the patients except case CA had neurological damage secondary to the scoliosis. Recordings were made in the operating theatres of the Hospital for Sick Children or of King's College Hospital. The children were ventilated following a routine anaesthetic induction with thiopentone $(5 \mathrm{mg} / \mathrm{kg})$ and suxamethonium $(1-2 \mathrm{mg} / \mathrm{kg})$ and anaesthesia was maintained using nitrous oxide $(70 \%)$, oxygen $(30 \%)$ and halothane (approximately $0 \cdot 5 \%$ ). Intermittent boluses of tubo-curarine and fentonyl were administered during the procedure.

A Digitimer D180 stimulator was used to activate descending pathways via two $\mathrm{Ag} / \mathrm{AgCl}$ electrodes fixed to the scalp with collodion. The cathode was placed at the vertex and the anode $7 \mathrm{~cm}$ lateral to it, approximately over the hand area of motor cortex. In the figures, stimulator output is graded in arbitrary but linear units from 0-10. It is produced by a capacitative discharge which may have a time constant of 50 or $100 \mu \mathrm{s}$. In the present study only $50 \mu \mathrm{s}$ discharges were used. Maximum output, " $10 "$, is $700 \mathrm{~V}$ with a peak current of about $500 \mathrm{~mA}$. Stimuli were delivered manually at intervals greater than $5 \mathrm{~s}$. Sensory function in ascending pathways was assessed using percutaneous stimulation of the left or right tibial nerve in the popliteal fossa. Constant voltage stimuli (Devices 3073 stimulator) of $100 \mathrm{~ms}$ duration and $60-120 \mathrm{~V}$ were delivered at a rate of $21 \cdot 1 \mathrm{~Hz}$.
Recordings were made from bipolar electrodes (USCI 4F cardiac pacing electrodes; interelectrode distance $1 \mathrm{~cm}$ ). During the operation, a 14G "Medicut" cannula was inserted through the exposed dorsal interspinous ligament. The electrodes were then fed through the cannula to lie in the epidural space over the dorsal surface of the spinal cord. Depending upon the length of the operation and the condition of the patient, it was not always possible to perform all the tests in each case. Cervical electrodes were introduced in all patients; in three of them another electrode was placed in the low thoracic region. In three cases an hexapolar electrode (Berkovitz-Castellanos) was inserted into the oesophagus, to lie at mid-thoracic level. In the initial experiments, signals were amplified and averaged using a Nicolet CA1000 averaging system with Nicolet HGA 200A amplifiers. Later experiments were analysed using a Digitimer D200 system. In all cases the amplified signals also were recorded on a Racal Store 7DS instrumentation tape recorder with a flat frequency response from $\mathrm{DC}-2 \cdot 5 \mathrm{kHz}$. This data was replayed later and analysed with a PDP 12 computer. All the figures were drawn using this latter method.

Responses from each single shock to the scalp area overlying the motor cortex were recorded using a bandpass of $30-3000 \mathrm{~Hz}$. Sensory potentials to tibial nerve stimuli were recorded with a bandpass of $150-3000 \mathrm{~Hz}$ in averages of 256-512 sweeps. When it was necessary to compare velocities in afferent and efferent pathways both sets of responses were recorded with a bandpass of $150-3000 \mathrm{~Hz}$. Descending nerve volleys, were recorded so that a negative potential at the proximal electrode produced an upward deflection at the final output. Electrode polarities were reversed when ascending volleys were recorded. Latencies were measured to the peak of each potential since the onset of the waves was difficult to define especially when following a large stimulus artefact. The potentials did not change in duration or shape at higher stimulation intensities, although they increased in amplitude. Thus, measurements of conduction velocity would have been the same whether peak latencies or onset latencies were measured. 


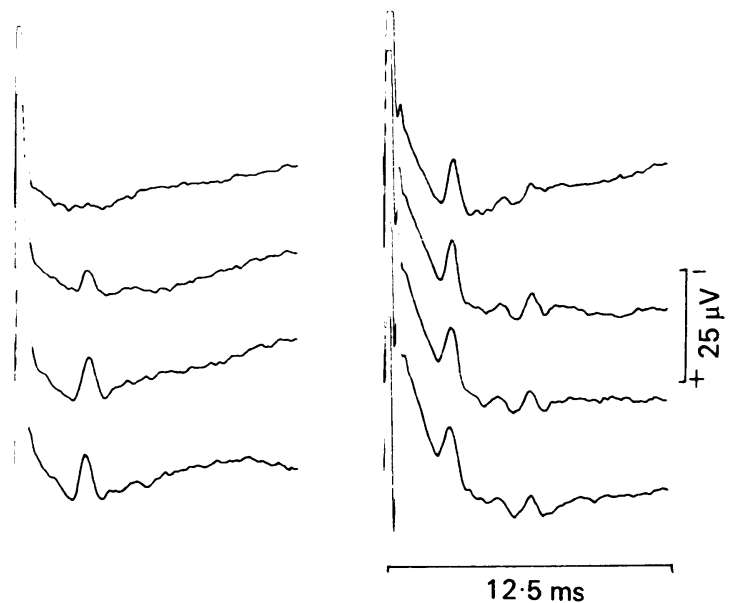

Fig. 1 Spinal cord potentials recorded from bipolar epidural electrode at the level of the mid-cervical cord following scalp stimulation at intensities from " 3 to 10". A short latency negative wave appears at low stimulation intensities, which increases in size and decreases in latency as the stimulation strength is raised. The amplitude of the wave saturates at intensities 7-10, and a small later negative wave appears with a peak latency of $7 \mathrm{~ms}$. Traces are single sweeps. Stimulation occurs at the start of each record. (Patient KA).
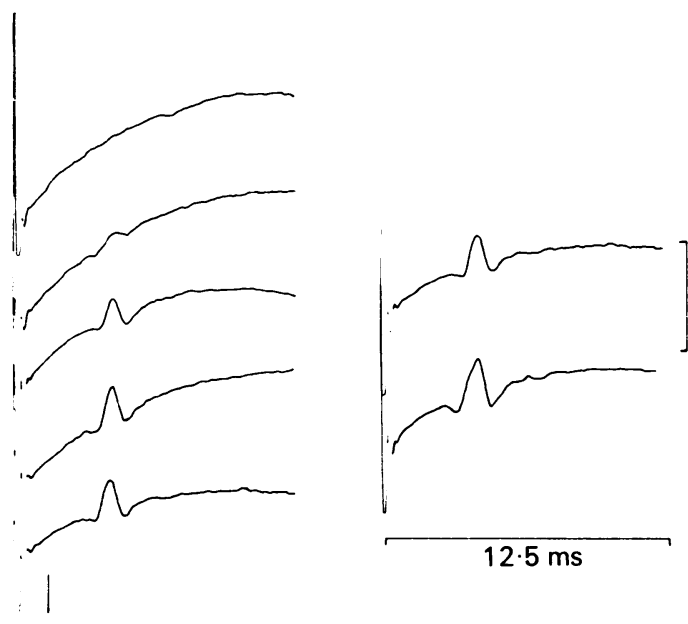

Fig. 2 Spinal cord potentials recorded from bipolar epidural electrode at the level of the mid thoracic cord. A, shows effect of increasing intensity of scalp stimulation from " 6 to 10 ". $B$, show's effect of reversing polarity of scalp stimulation at intensity " 10 ". Upper trace (also all traces in A) with cathode at vertex and anode over hand area; lower trace anode at vertex, cathode over hand area. Each trace is the average of 5 trials. (Patient EL).

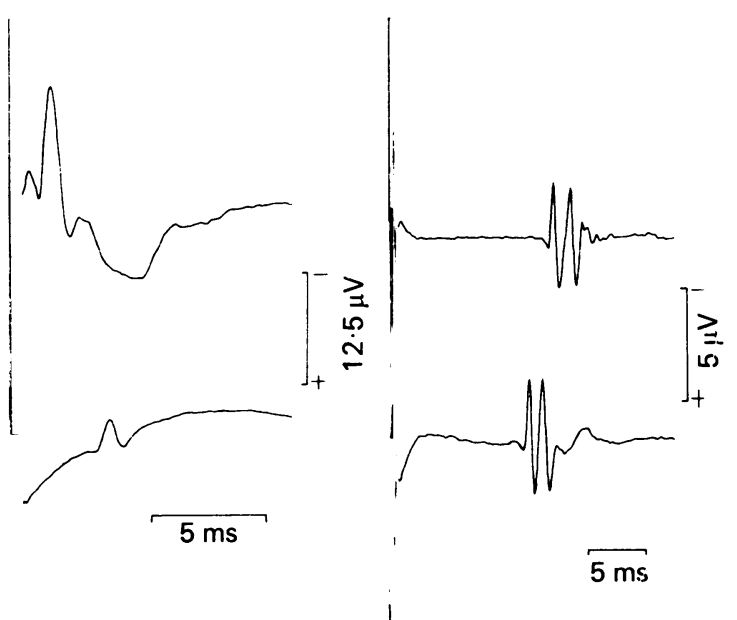

Fig. 3 Descending motor volleys ( $A$ ) and ascending sensory volleys $(B)$ recorded from two bipolar electrodes in the high cervical and mid thoracic epidural spaces of one patient. Motor volley's were produced by scalp stimulation, sensory volleys by percutaneous stimulation to the tibial nerve in the popliteal fossa. The interelectrode distance was $18.5 \mathrm{~cm}$ as measured over the vertebral bodies. The conduction delay for the motor potentials was $2.6 \mathrm{~ms}$, whereas it was $2.1 \mathrm{~ms}$ (first peak) or $2.5 \mathrm{~ms}$ (second peak) for the sensory potentials. Motor volleys are the average of 5 sweeps; sensory volleys the average of 500 sweeps. In $(A)$, scalp stimulation intensity was the minimum needed to evoke reproducible volleys at thoracic levels. The conduction velocity at this intensity was the same as that measured at maximum stimulation strength (see results in table 2). (Patient EL).

\section{Results}

It was easy to record electrical responses at all levels in the spinal cord following single stimuli applied to the scalp over the motor strip. At cervical levels, this consisted of a negative wave which appeared at very low intensities of stimulation. In different patients it had a latency varying from $1.7-3.8 \mathrm{~ms}$, depending upon the level of the recording electrode. The potential increased in size as the stimulation intensity increased. Later components were seen with higher intensities. Their morphology was very variable and they occurred at approximately twice the latency of first peak. The latency of the first deflection decreased by an average of $0.3 \mathrm{~ms}$ over the full range of intensities, and its amplitude appeared to approach saturation at the highest intensities of stimulation (fig. 1). In four of the patients, the first wave had a biphasic appearance at high intensities which was not present at lower intensities.

Responses at thoracic levels were much smaller, and had a higher threshold for their appearance. In 
one patient we were able to verify that the peak latency in the thoracic region decreased at higher levels of stimulation, similar to the wave at cervical levels, and appeared to saturate at maximum intensity. No later waves were visible at the thoracic level of the cord (fig. 2A). The size of the low thoracic responses was increased slightly by reversing the polarity of scalp stimulation, so that the anode lay over the vertex (fig 2B).

Two methods were used to calculate motor conduction velocities in corticospinal pathways. Where two electrodes were used, the conduction velocity was calculated from the interpeak latency and the inter-electrode distance as measured over the surface of the spinal column (fig $3 A$ ). When only one electrode was used, a response was recorded and the electrode was then moved distally $1-2 \mathrm{~cm}$ before a subsequent response was recorded. The difference in peak latency over the known distance that the electrode had been moved, then was used to calculate the motor conduction velocity (fig 4). The results are summarised in table 2 . The patient illustrated in fig 3 was the only individual with two recording electrodes in whom it was possible to measure the conduction time between the recording sites at different intensities of cortical stimulation. The figure shows the latency at the stimulation strength ("7") necessary to evoke minimal reproducible thoracic potentials. The interelectrode latency was the same at maximal intensity (see table 1), even though the volleys at cervical and thoracic level occurred some $0.2 \mathrm{~ms}$ sooner. Because of this, measured conduction velocity of the fibres between the electrodes was the same at all stimulation intensities. When conduction velocity was measured by moving the cervical electrode a known distance it was not possible to measure peak latency with sufficient accuracy to test whether stimulation intensity affected the result.

In three patients in whom two recording electrodes were used it was possible to compare the conduction time of afferent impulses produced by tibial nerve stimulation and efferent impulses following scalp stimulation between cervical and low thoracic levels (table 2). The motor and sensory conduction velocities were very similar in all three cases. In one patient, the velocity of the descending volley was slower than that of the fastest ascending sensory volley, but was almost the same as that of the second component of the sensory volley (fig 3B).

A less invasive form of spinal monitoring, using an oesophageal electrode was attempted with three of the patients. In one of these we failed to record any recognisable signals from the oesophagus following either form of stimulation, even though the epidural electrodes indicated that a strong signal was present. In the second, only sensory potentials were visible: a

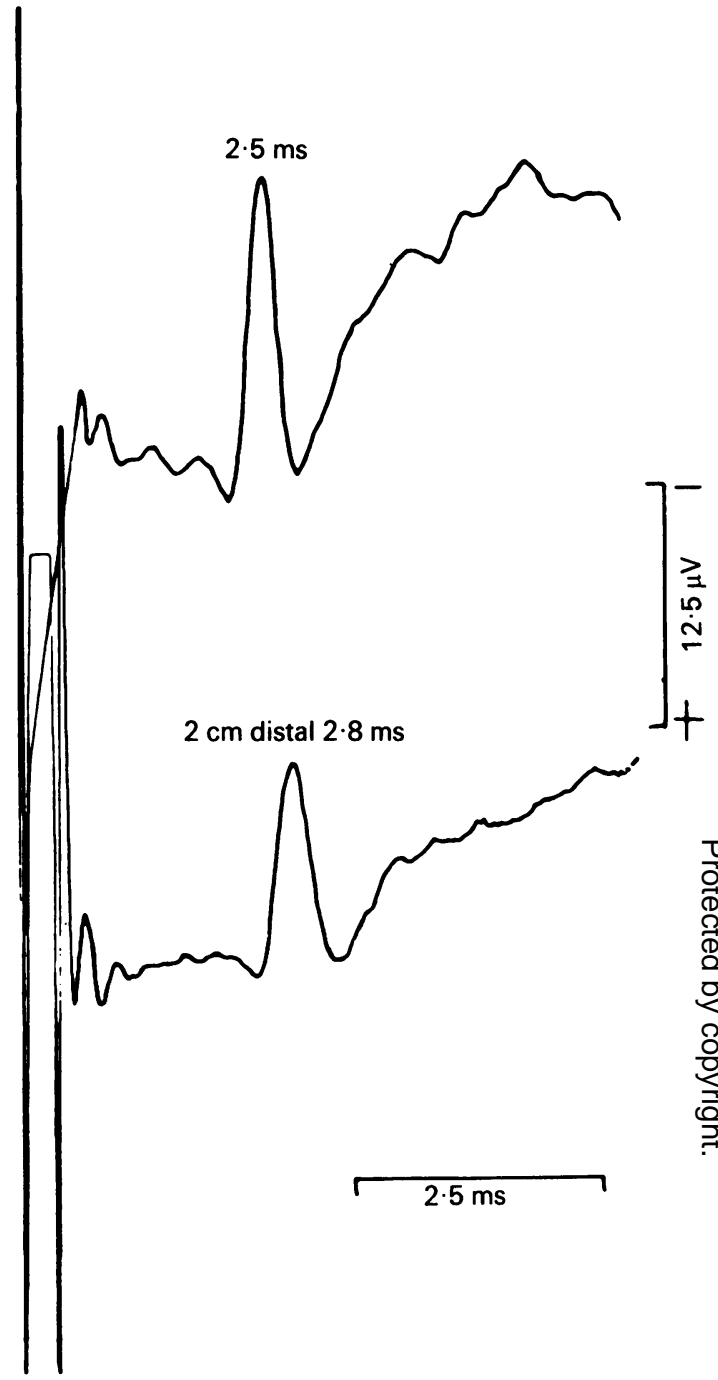

Fig. 4 Effect of moving a bipolar recording electrode in the cervical epidural space on the latency of the first negative potential produced by scalp stimulation. A latency difference of $0.3 \mathrm{~ms}$ over $2 \mathrm{~cm}$ gives a conduction velocity of $67 \mathrm{~ms}^{-1}$.

Traces are the average of 5 sweeps. In this illustration, scalp stimulation was submaximal. The same latency difference was measured at maximal intensity, although the stimulus artefact was much larger. (Patient $\mathrm{LH}$ ).

large artefact obscured the response to scalp stimulation. However, in the third, clear ascending and descending potentials were visible, which were only $30-50 \%$ smaller than those recorded directly from the epidural space (fig 5).

Finally, an opportunity was taken to record from the epidural space of a patient who had been rendered 
Table 2 Conduction times and velocities of spinal cord potentials recorded from electrodes inserted in the epidural space

\begin{tabular}{|c|c|c|c|c|c|c|c|}
\hline \multirow[t]{2}{*}{ Patient } & \multicolumn{4}{|c|}{ Latency after scalp stimulation } & \multicolumn{2}{|c|}{$\begin{array}{l}\text { Estimated conduction velocity } \\
\operatorname{Motor}\left(m s^{-1}\right)\end{array}$} & \multirow[b]{2}{*}{ Sensory $\left(\mathrm{ms}^{-1}\right.$} \\
\hline & $\begin{array}{l}\text { Cervica } \\
\text { Max }\end{array}$ & Min & $\begin{array}{l}\text { Lumb } \\
\text { Max }\end{array}$ & Min & $\begin{array}{l}\text { Motor }\left(\mathrm{ms}^{-1}\right) \\
\text { Moving cervical } \\
\text { electrode }\end{array}$ & $\begin{array}{l}\text { Simultaneous recording } \\
\text { from } 2 \text { electrodes }\end{array}$ & \\
\hline LH & $2 \cdot 7$ & $2 \cdot 4$ & & & 67 & & \\
\hline $\mathrm{EL}$ & 2 & $1 \cdot 7$ & $4 \cdot 5$ & $4 \cdot 3$ & & 71 & $\begin{array}{l}88 \text { (1st peak) } \\
74 \text { ( } 2 \text { nd peak) }\end{array}$ \\
\hline SB & $3 \cdot 1$ & $2 \cdot 8$ & & & 67 & & \\
\hline PH & $3 \cdot 2$ & $3 \cdot 2$ & & & 50 & & \\
\hline KA & $3 \cdot 2$ & 2.9 & & & & & \\
\hline DK & $3 \cdot 8$ & $3 \cdot 4$ & & & & & \\
\hline WJ & 2.9 & $2 \cdot 1$ & & $5 \cdot 3$ & & 74 & 76 \\
\hline $\mathrm{AR}$ & $2 \cdot 7$ & $2 \cdot 5$ & & $7 \cdot 7$ & & 58 & 52 \\
\hline
\end{tabular}

Sensory conduction velocity was measured only when two recording electrodes were inserted. Minimum latencies are values to peak negative potentials at maximum stimulation intensity. Maximum latencies were measured at the lowest intensity needed to produce a reliable spinal potential.

paraplegic at the T6 level after a previous operation. Ascending sensory volleys were seen only at the low thoracic electrode. Descending volleys produced by scalp stimulation only appeared at the cervical electrode (fig 6).

\section{Discussion}

Stimulation of the scalp with single high voltage stimuli produced clear electrical potentials at all levels of the spinal cord. Movement of the epidural recording electrodes changed the latency of these negative potentials and interruption of the cord abolished responses below the level of the lesion, indicating that they represented a wave of depolarisation which travels down the cord. Their relatively short time
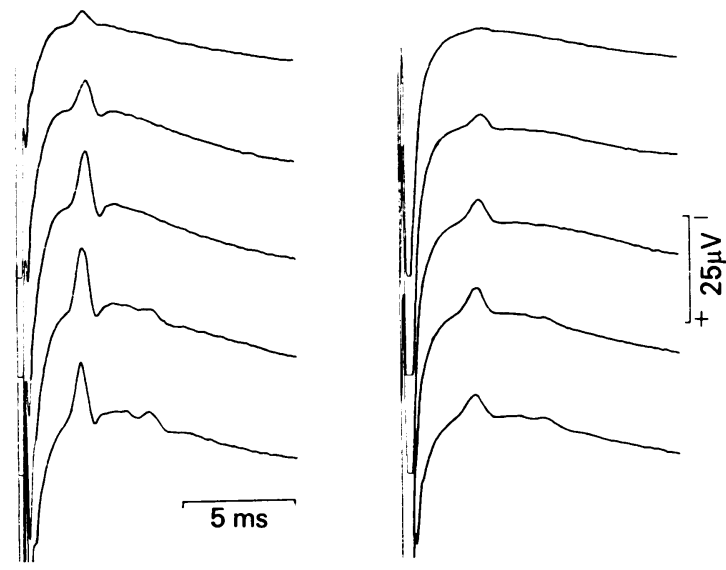

Fig. 5 Comparison of responses recorded from a bipolar electrode in the cervical epidural space and bipolar oesophogeal electrode following scalp stimulation at 5 different intensities from " 2 to 9 ". Single sweeps. (Patient $S B$ ). course, when recorded with open filter settings suggests that they were not synaptic potentials, but were descending nerve volleys.

In conscious subjects, scalp stimulation undoubtedly activates motor pathways. ${ }^{1416}$ At high intensities, visible muscle contractions can be produced, whilst at lower intensities, sub-threshold excitability changes in alpha-motoneurones can be detected using monosynaptic testing. ${ }^{17}$ It is not certain at what level (cortex, internal capsule, or even

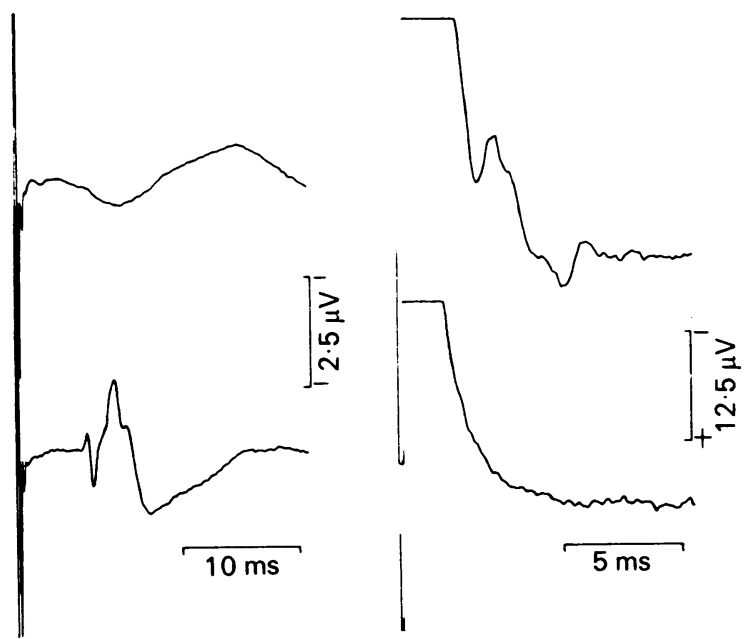

Fig. 6 Ascending sensory volleys (left) and descending motor volleys (right) recorded from bipolar epidural electrodes in the high and low thoracic epidural space in a patient who had been rendered paraplegic at the T6 level in a previous operation. The volleys are not conducted past the region of block. Sensory potentials are the average of 500 sweeps; motor potentials are the average of 5 sweeps. The sensory potentials have an abnormal morphology (compare fig 3). (Patient CA). 
brainstem) stimulation occurs using this technique. Two lines of evidence suggest that corticospinal fibres are being activated at the cortical or just sub-cortical level. First, maximum effects occur when the stimulator is placed over the motor strip. The lowest threshold point for hand muscle activation is found in the mid-lateral part of the motor strip, whereas it is at the vertex for activation of the muscles of the leg and foot. ${ }^{14}$ Second, scalp stimulation activates the contralateral distal musculature preferentially, particularly the small muscles of the hand. ${ }^{14}$ Other than direct corticomotoneuron pathways, only the rubrospinal tract is known to have such a selective projection, but is rudimentary or absent in man. ${ }^{18}$ Reticulospinal fibres, which could be activated by cortical efferent axons do not have such a distribution.

The volleys recorded at spinal level in the present patients most probably represent the descending volley which is responsible for the motor effects seen in conscious man. Anaesthesia probably has little effect on this relatively simple pathway. Threshold for production of the volley is similar to the threshold for effects on spinal alpha-motoneurone excitability. ${ }^{19}$ The latency of the descending volley is the same as that predicted from experiments in conscious man, when the motoneuronal synaptic delay is taken into account. ${ }^{1420}$ It is very unlikely that the descending volley could have had any significant contribution from activity in sensory pathways. Antidromic stimulation of dorsal column fibres would have to have occurred below the level of the dorsal column nuclei, which seems unlikely in view of the arguments above. A contribution from spinothalamic activation is equally unlikely in view of the importance of correct placement of the stimulating electrodes on the scalp.

Several features of the epidural potentials that we have recorded deserve comment. First, the size of the potentials was large and synchronous, as expected from a volley recorded in a pathway without intervening synapses. Second, as stimulation intensity was raised, the latency of the volley decreased. This could be due either to recruitment of faster-conducting axons or to spread of stimulation current to more distal parts of the cortical axon. If the decrease in latency were due to recruitment of faster conducting axons, then the conduction velocity measured between two recording sites on the spinal cord also should change as stimulation strength is raised. In the one patient in whom we were able to test this (EL; fig $3 \mathrm{~A})$, conduction velocity was independent of stimulation intensity. This isolated observation needs to be confirmed. However, if the decrease in latency is due to activation of more distal parts of the axon, then a decrease in latency of $0.3 \mathrm{~ms}$ in a fibre conducting at $60 \mathrm{~ms}^{-1}$ would imply that the stimulus current could spread $18 \mathrm{~mm}$ into the depths of the white matter at maximum intensity. Third, the size of the spinal potential was much smaller at thoracic than cervical levels. Although some of this decrease undoubtedly was due to dispersion of the volley as it travelled down the cord, another important factor is likely to be the known lower density of corticospinal tract projections to lumbar as compared with cervical cord.

The presence of variable, small, later waves in the epidural records has several possible explanations. They are unlikely to be artefacts due to muscle contraction produced by the stimulation since the patients were completely paralysed when the recordings were made. They may have been due, for example, to activity in indirect pathways, or to repetitive activity in corticospinal neurones. They bear a close resemblance to the I wave recorded from pyramidal tract after anodal stimulation of exposed cortex in primates. The latency is about twice that of the $D$ (initial) wave and the threshold stimulation intensity is higher. Such I waves have been shown to be due to repetitive activation of corticospinal axons. ${ }^{21}$

The estimates of motor conduction velocity in the patients in this series ranged between 50 and $74 \mathrm{~ms}^{-1}$ This compares with an indirect estimate of about $50 \mathrm{~ms}^{-1}$ made in intact conscious adults by Marsden $e a^{22}$ using the same stimulation technique. They stimulated over the scalp and also over the cervical cord and estimated the difference in latency to thes onset of contraction in the same upper limb muscle. In contrast with this Levy and York ${ }^{10}$ using electrical stimulation of lateral spinal tracts, found motor con duction velocities well in excess of $100 \mathrm{~ms}^{-1}$ However their technique involved direct stimulation of the surface of the exposed spinal cord, which would not permit specific stimulation of the corticospinal tracts alone. Furthermore, Desmedt and Cheron ${ }^{23}$ recently have observed that external measurements of the spinal column over-estimate the actual length of the spinal cord and this would make our value of $74 \mathrm{~ms}^{-1}$ for motor pathways an upper limit of conduction velocity in the spinal cord. Our values are similar to those obtained for conduction velocities in cortico-spinal pathways in monkeys. ${ }^{24}$

The possibility of isolated damage to either sensory or motor pathways during manipulation of the spinal column has already been mentioned, and is thought to be related to differences in blood supply to these tracts. ${ }^{825}$ In addition, there is some evidence that spinal cord blood flow may be already compromised in patients with severe scoliosis. ${ }^{26} \mathrm{We}$ believe that we now have the means to monitor both motor and sensory spinal pathways. It is hoped that use of the two complementary techniques during corrective spinal surgery will help to reduce neurological complications. In addition, the technique may prove of value in monitoring the motor pathways during intraspinal 
or intracranial neurosurgery.

This study was approved by the Ethical Committees of the Hospital for Sick Children and King's College Hospital. We should like to thank Dr E Facer for her help and advice. This work was supported by the MRC. JCR is a Royal Society University Research Fellow.

\section{References}

${ }^{1}$ MacEweb GD, Bunnell WP, Sviram K. Acute neurological complications in the treatment of scoliosis. J Bone Joint Surg (Am) 1975;57:404-8.

${ }^{2}$ Vauzelle C, Stagnara P, Jouvinroux P. Functional monitoring of spinal cord activity during spinal surgery. J Bone Joint Surg (Am) 1973;55:441.

${ }^{3}$ Homma S, Tamaki T. Fundamentals and Clinical Application of Spinal Cord Monitoring. Tokyo: Saikon Publishing Co, 1984.

${ }^{4}$ Maruyama Y, Shimoji K. Shimizu H, Kuribayashi H, Fujioka $\mathrm{H}$. Human spinal cord potentials evoked by different sources of stimulation and conduction velocities along the cord. J Neurophysiol 1982;48:1098-107.

${ }^{5}$ Shimuzu H, Shimoji K. Maruyama Y, Matsuki M, Kuribayashi H, Fujioka $H$. Human spinal cord potentials produced in lumbosacral enlargement by descending volleys. J Neurophysiol 1982;48:1108-20.

${ }^{6}$ Shimizu H, Shimoji K, Maruyama Y, Sato Y, Maruyama $H$, Tsubaki T. Slow cord dorsum potentials elicited by descending volleys in man. JNeurol Neurosurg Psychiatry 1979:42:242-6.

${ }^{7}$ Hanada Y, Takemitsu Y, Atsuta Y, Imai M. Intraspinal location of conductive spinal cord evoked potentials for spinal cord monitoring during surgery. In: Schramm J, Jones SJ, eds. Spinal Cord Monitoring. Springer Verlag (in press).

${ }^{8}$ Raudzens P. Intraoperative monitoring of evoked potentials. Ann NY Acad Sci 1982;388:308-26.

${ }^{9}$ Bennet MH. Effects of compression and ischemia on spinal cord evoked potentials. Exp Neurol 1983;80:508-19.

${ }^{10}$ Levy WJ. Spinal evoked potentials from the motor tracts. J Neurosurg 1983;58:38-44.

${ }^{11}$ Levy WJ, York DH. Evoked potentials from the motor tracts in humans. Neurosurg 1983;12:422-9.
${ }^{12}$ Levy WJ, McCaffrey M, York DH, Tanzer F. Motor evoked potentials from transcranial stimulation of the motor cortex in cats. Neurosurg 1984;15:214-27.

${ }^{13}$ Levy WJ, York DH, McCaffrey M, Tannzer F. Motor evoked potentials from transcranial stimulation of the motor cortex in humans. Neurosurg 1984;15:287-302.

${ }^{14}$ Merton PA, Morton HB. Stimulation of the cerebral cortex in the intact human subject. Nature 1980;285:227.

${ }^{15}$ Boyd S. Cowan J, Marsden CD, Rothwell JC, Webb PJ. Direct estimation of corticospinal tract conduction velocity in man. J Physiol (Lond) 1985;358:36P.

${ }^{16}$ Merton PA, Morton HB, Hill DK, Marsden CD. Scope of a technique for electrical stimulation of human brain, spinal cord and muscle. Lancet 1982;ii:597-600.

${ }^{17}$ Cowan J, Day BL, Marsden CD, Rothwell JC. Effect of sub-threshold motor cortical shocks on the human spinal monosynaptic reflex. J Physiol 1983;341:32-33P.

${ }^{18}$ Nathan PW, Smith MC. The rubrospinal and central tegmental tracts in man. Brain 1982:105:223-269.

${ }^{19}$ Berardelli A, Cowan JMA, Day BL, Dick J, Rothwell JC. The site of facilitation of the response to cortical stimulation during voluntary contraction in man. J Physiol (Lond) 1985;360:52P.

${ }^{20}$ Cowan JMA, Dick JPR, Day BL, Rothwell JC, Thompson PD, Marsden CD. Abnormalities in central motor pathway conduction in multiple sclerosis. Lancet 1984;ii:304-7.

${ }^{21}$ Landau WM, Bishop GH, Clare MH. Site of excitation in stimulation of the motor cortex. J Neurophysiol 1966;29:1206-22.

${ }^{22}$ Marsden CD, Merton PA, Morton HB. Percutaneous stimulation of spinal cord and brain: pyramidal tract conduction velocities in man. J Phvsiol 1982;328:61P.

${ }^{23}$ Desmedı JE, Cheron G. Spinal and far-field components of human somatosensory evoked potentials to posterior tibial nerve stimulation analysed with oesophageal derivatives and non-cephalic reference recording. Electroencephalogr Clin Neurophysiol 1983;56:635-51.

${ }^{24}$ Phillips CG, Porter R. Corticospinal Neurones. London: Academic Press, 1977;268.

${ }^{25}$ Turnbull I, Brieg A, Hassler O. Blood supply of cervical spinal cord in man: A microangiographic study. J Neurosurg 1966;24:951-65.

${ }^{26} \mathrm{Keim}$ HA, Hilal SK. Spinal angiography in scoliosis patients. J Bone Joint Surg (Am) 1971;53:904-12. 